\begin{tabular}{|l|c|c|}
\hline Volume 5, Number 7 & Research Question Review & 31 DECEMBER 2021 \\
\hline
\end{tabular}

\title{
Methods of Assessing Intercultural Compe- tence for International Assignments: A Systematic Review of Reviews
}

By

John Hennings, University of South Florida

$\mathrm{D}$ espite the high cost and high frequency of failure in expatriate assignments, the potential value and opportunity gained by sending employees overseas is driving the number of business expatriates skyward. One way organizations can significantly mitigate risk is by assessing and selecting candidates for intercultural competence. Intercultural competence has affective, cognitive, and conative aspects. It can be measured via inventory or survey instruments, works of creative self-expression, dialogue, case study or critical incident analysis, and performance in real or contrived situations, but each approach has strengths and weaknesses. Experts recommend multiple assessments via mixed methods.

Survey instruments have become prevalent in business because they are simple, quick, inexpensive, and yield easily comparable results. The author of this article conducts a review of reviews, or meta-review, of available survey instruments. Out of several dozen surveys, five

The rewards of sending personnel on overseas assignment can be high, but so can the risks. How can organizations cost effectively assess and select the right person? met the criteria for review in this article, and three proved more valid and reliable than their peers. The author closes by discussing the services of global mobility consultants with proprietary assessment and training methods, then making recommendations for candidate selection processes based on risk tolerance, resources available, and the magnitude of the requirement.

Keywords: Intercultural Competence, Cultural Intelligence, Intercultural Adaptability, International Assignments, Business Expatriates, Meta-review, Assessment, Instrument, Selection 
Successful expatriate managers create value and opportunity, transfer knowledge, enhance communication, and enable better control (Collings et al., 2007, p. 6; Feitosa et al., 2014, p. 4). So although expatriation is the costliest staffing option for multinationals (Selmer, 2001), international assignments will continue to multiply. About $63 \%$ of companies saw their number of expatriate employees stay the same or increase between 2014 and 2015, and 75\% expected that number to stay the same or increase through 2017 (Brookfield, 2016, p. 48). Many firms now require international experience for advancement to senior management (Mesmer-Magnus \& Viswesvaran, 2008, pp. 189-190). The most recent (post-COVID-19 pandemic) information shows 1) a significant reduction in expatriate assignments, 2) a greater use of technology to work together virtually across national boundaries, and 3) increased attention and priority for the remaining global mobility assignments. International teleworking requires far less initial resource outlay, but it may offer far less utility (Dickmann, 2021). It also demands the same intercultural competence that expatriate assignments do but with extremely diminished opportunity to learn the cultures, personalities, and circumstances involved.

Expatriate failure is common and costly. Sixteen to forty percent of expatriate assignments fail to accomplish company goals, often due to ineffective adjustment and relationship-building. Overall, about 20\% return home early, and from developing nations, the estimate is 70\% (Graf \& Harland, 2005). Estimated costs for a typical failure (lost business, preparation expenses, etc.) run between $\$ 250,000$ and $\$ 1.25$ million. Such a failure can also devastate the career and self-esteem of a once-promising assignee (Mesmer-Magnus \& Viswesvaran, 2008).

Research commonly cites lack of intercultural competence as a primary reason for expatriate failure (Bird et al., 2010; Gertsen, 1990; Johnson, Lenartowicz, Apud, 2006; Josien, 2012; Kraimer, Bolino, \& Mead, 2016; Peltokorpi \& Froese, 2012). However, despite a body of research recommending formal assessments of intercultural competence for expatriate assignees, businesses frequently ignore intercultural competence and focus overwhelmingly on technical competence, or knowledge of the functions and processes of the overseas element (Graf \& Harland, 2005; Kraimer, Bolino, \& Mead, 2016; Mesmer-Magnus \& Viswesvaran, 2008; Peltokorpi \& Froese, 2012). Researchers were already identifying reasons for this emphasis decades ago. Dr. Rosalie Tung (1981) summarized them as follows:

- Technical competence is even more important for expatriates, because it is more difficult to consult with knowledgeable colleagues remotely.
- Many of those involved in selection do not realize that relational criteria are measurable.

- Some organizations expect language and cultural training to fill any capability gaps. They do not anticipate that some candidates may be more likely than others to benefit from and adopt the lessons of training.

- It is possible that some selectors believe that a lack of technical competence will drive failure more quickly than other issues and that a rapid failure would reflect negatively on the selector.

In 1999, Harris and Brewster posited that the over-focus on technical proficiency may spring from desperation. They suggested that selectors are aware of the inherent risks of expatriate assignments but unaware of what non-technical criteria they should be measuring. Consequently, they double down on the criteria they can identify.

This article will outline the different approaches to intercultural competence assessments and describe the strengths and weaknesses of each. It will then provide a meta-review of the most common assessment instruments prevalent in the literature and make recommendations on the assessment methods most suitable for use in practice. The latter section will answer the research question, "What instruments may organizations use to evaluate intercultural competence in the selection process?"

\section{Description of Approaches}

As a construct, intercultural competence can be defined as "the ability to grasp different cultures, interact appropriately within them, and work effectively." Alternate terms for similar or equivalent constructs include cross-cultural competence, cultural agility, intercultural adaptability, and cultural intelligence, among others (Fantini, 2009, p. 457; Deardorff, 2011, p. 65). The most widely cited frameworks for intercultural competence demarcate three to five dimensions. The motivational or affective dimension involves values, motivations, and interests. It provides the will and capacity to develop and employ intercultural competence. The cognitive dimension is the one most often broken out into additional dimensions, as it involves culture-specific knowledge, culture-general knowledge, and metacognition how one learns, thinks about, and interprets cultural knowledge and behavior. The conative or behavioral dimension encompasses skill and behavior - how one speaks and acts (Hennings, 2018). Unless explicitly stated, this article will discuss only assessment methods based on frameworks similar to this one. Even within that set, however, some methods focus on some aspects of intercultural competence more than others.

When selecting any method of assessment, the organization must match what they want the assessment to accomplish with the framework or model 
upon which a particular assessment is based. (Fantini, 2009, pp. 460-461, 465; Deardorff, 2011, p. 65, 73). The first goal of assessment is usually informing selection - identifying candidates suitable for preparation and deployment as assigned expatriates. The second is informing preparation. Intercultural competence has proven somewhat malleable in that education, training, and experience can significantly improve it, despite a lack of consensus regarding the best methods of doing so (Griffith et al., 2016, pp. 6-7; Mesmer-Magnus \& Viswesvaran, 2008, p. 185). Some researchers suggest a candidate should complete assessments prior to language and culture training - ideally, rigorous, thorough assessments that provide detailed feedback so the curriculum may be tailored to the candidate's needs. However, one meta-analysis concluded that this rarely occurs (Mesmer-Magnus \& Viswesvaran, 2008, p. 185; Feitosa et al., 2014, p. 142).

The particular requirements of the assignment should inform every step of this process. Intercultural competence in general is always desirable, but may be less important when the sending and receiving cultures are similar (e.g., Canada and the United Kingdom). Similarly, some aspects of intercultural competence may be more important than others for a particular assignment. Those distinctions should be identified early on and taken into consideration when selecting methods of assessment (Fantini, 2009, p. 465). For example, an American assigned to live and work in Japan must be able to adapt to a high power distance, high context culture, where rank is extremely significant and communication is indirect (Hofstede, 1983, pp. 50-55). If available, the experiences of previous assignees in similar locations and positions can be a useful guide for what is required. It's important to note that firms have the option of outsourcing assessment and training to service providers in the global mobility industry. If they choose to do so, they should ensure that their consultants' solutions meet their needs and are not one size fits all.

Decades of studies of intercultural competence have generated a surfeit of approaches for evaluating it (Yu, 2012, p. 169; Fantini, 2009, p.464; Deardorff \& Deardorff, 2007, p. 93; Deardorff, 2009, p. 482; Cantele et al., 2015, p. 24; Griffith et al., 2016, pp. 7-15). This review will assess the applicability of those approaches to the selection of expatriate assignees. However, it is important to note that intercultural competence should not be the only factor in selection. This review has already lamented the emphasis on technical and professional competence at the expense of other considerations. Nevertheless, those qualities are admittedly critical (Mesmer-Magnus \& Viswesvaran, 2008, p. 187; Feitosa et al., 2014, p. 140). Other weighty dynamics include (but are not limited to) the following:
- Cultural distance, or the degree of difference between the cultures of the assignee and the receiving hosts (Nelson, 2019; Linville, 2012; Mesmer-Magnus \& Viswesvaran, 2008, pp. 188-189, 194)

- Individual cultural orientation - personality traits that make a person more adaptable to some cultures than others (Linville, 2012; Mesmer-Magnus \& Viswesvaran, 2008, pp. 184-185)

- The intercultural competence and cultural orientation of the assignee's family members (Mesmer-Magnus \& Viswesvaran, 2008, pp. 187-189, 193-194; Feitosa et al., 2014, pp. 137, 147; Nelson, 2019)

- The practical global mobility considerations of the entire family - i.e., their physical, mental, and emotional readiness to live and work in the target environment (Magnus \& Viswesvaran, 2008, p. 189; McNulty et al., 2013)

- State fragility - i.e., the degree to which security, rule of law, economic opportunity, and basic services are in question (Nelson, 2019)

The practical considerations in the penultimate bullet above include everything from crime rates to requisite medical care to job opportunities to schooling. Organizations must consider these issues on a caseby-case basis, because they vary in each location and for each family.

The leading lights in the study of intercultural competence recommend assessing a mix of quantitative and qualitative data (Deardorff, 2006, p. 241). The most prevalent approaches are to assess the following (Yu, 2012, p. 169; Fantini, 2009, p. 464; Deardorff \& Deardorff, 2007, p. 93; Deardorff, 2009, p. 482; Cantele et al., 2015, p. 24):

a) self-reporting through inventory or survey instruments

b) works of creative self-expression

c) dialogue

d) case study or critical incident analysis

e) performance in real or contrived situations

Inventory/survey instruments are the most common quantitative approach, while the rest are generally qualitative. However, there is variation within each category, and as the structure of data collection increases and the latitude of responses decreases, the methods increasingly behave as quantitative instruments. The corresponding advantages and disadvantages of each extreme (covered below under Works of Creative Self-Expression) arise accordingly. Instructors frequently use methods on the more qualitative end of the spectrum to help develop intercultural competence as well as assess it.

In recent years, researchers have identified less intuitive, but potentially no less valid measures and indicators, such as social network analysis (Chi \& Suthers, 2015). This article will focus on strategies 
currently considered conventional, i.e., those for which there is a deeper history of study and use. However, the utility of this review is finite in time, because research is continually moving forward.

\section{Self-Reporting Through Inventory or Survey Instruments}

These instruments typically consist of statements or questions with Likert scale or, less often, multiple choice responses. They are the most common method of assessing intercultural competence discussed in the literature, and they are in wide use (Yu, 2012, p. 176; Griffith et al., 2016, p. 31) for multiple reasons. They are quick, easy to use (Deardorff \& Deardorff, 2007, p. 91; Dervin, 2010, p. 8) and often inexpensive, although some require trained proctoring and scoring (Paige, 2004, p. 91). They are also uniform across every assessment, which facilitates performance comparisons (Griffith et al., 2016, p. 12 ) and testing for validity and reliability. There are a great variety (Fantini, 2009, p. 465), so if a particular aspect of intercultural competence is desired, one can choose an instrument focused on assessing that component.

However, survey instruments have limitations. Some researchers have proposed that the near-ubiquitous Likert scale responses (often ranging from "strongly agree" to "strongly disagree") can effectively measure the motivational dimension, but multiple choice or forced responses (e.g., "Select the statement that best describes you") are more effective at measuring the cognitive and conative dimensions (Griffith et al., p. 12). Surveys also suffer from the cognitive bias problems inherent to all self-reporting-especially social desirability bias. Social desirability bias is the tendency to give the answer that the respondent believes is viewed most favorably. At its most extreme, social desirability bias can lead subjects to deliberately falsify responses. Inexperience can also degrade validity, as a person may be asked to describe his usual response to a situation he has never experienced. These weaknesses can create a gap between what a person reports about her ideas, attitudes, and actions and how the person will actually think, feel, and behave in a cross-cultural situation (Yu, 2012, p. 178; Griffith et al., 2016, p. 23; Dervin, 2010, p. 23).

\section{Works of Creative Self-Expression}

This category includes a wide variety of written works, especially critical reflections of cross-cultural experiences, journal entries, blogs, papers on cultural topics, and autoethnographies. It can also include photo essays and video and audio recordings. Academic settings use these extensively, because they require creative work to measure student learning and they are staffed to receive it and evaluate it. These artifacts - along with the products of other approaches on this list, such as inventories, critical incident reflections, and performance evaluations - can be gathered into portfolios and assessed collectively, as well as individually (Yu, 2012, p. 175-176; Griffith et al., 2016, p. 23; Deardorff, 2009; Deardorff, 2011; Fantini, 2009; Cantele et al., 2015, p. 24).

Individual artifacts and portfolios of creative self-expression are the opposite in every respect from inventory instruments. Works of self-expression are exceptionally flexible and can be tailored to the assessors' priorities. They provide context and depth and are consequently difficult to fake. Because portfolios can include multiple measurement approaches (e.g., autoethnographies, surveys, or critical incident analyses), they facilitate triangulation. This can significantly increase the confidence level of an assessment (Sutton et al., 2007, p. 33)

However, portfolios require a qualified evaluator and a rubric (e.g., http://www.aacu.org/value/rubrics/) to measure them by, and there is a considerable time cost for both the subject and the evaluator. And as each artifact or portfolio is unique, any comparison across individuals is debatable (Fantini, 2009, p. 464; Yu, 2012, p. 175-176; Griffith et al., 2016, pp. $7-8$ ). Finally, the nature of such work may "tell us more about students' language, analytical, and overall academic skills than about their intercultural competence" (Yu, 2012, p. 173; Dervin, 2010, p. 9). These strengths and weaknesses do not preclude the assessment of works of creative self-expression in practice; however, in many cases, they will make this approach more suitable to the academy than practice.

\section{Dialogue}

"Dialogue" in this case includes interviews, focus groups, debate, and any discussion-based assessment (Fantini, 2009, p. 464). One or more of these qualitative methods are often used in conjunction with more quantitative self-assessment instruments (Cartwright, 2016, pp. 7, 12; Fantini Appendix F, 2006, pp. 89, 91; Deardorff, 2006, p. 241). Even by themselves, dialogue-based assessments are a rich source of data. Students are both less inclined and less able to adjust their responses for social desirability, and interviewers can assess both nonverbal and verbal responses. The less structure, the more telling (and often more unexpected) data will result, but the more difficult the results are to assess reliably (Yu, 2012, p. 180). The conduct and interpretation of these assessments generally requires a trained professional. That person represents an expense, whether he or she is part of the organization or an external service provider. Given the far higher cost of expatriate failure, the expense may be a prudent one.

\section{Case Study or Critical Incident Analysis}

In these assessments, the subject receives a scenario involving intercultural interaction and responds 
with his or her analysis - how culture is a factor, what is being done right or wrong, and what the most effective next steps would be. These scenarios provide context, and that context is the basis for all their strengths. It enables the assessment to get one step closer to reality than in an inventory or interview, with a potential corresponding increase in validity. Unlike many of the works of creative self-expression, this approach isolates intercultural competence somewhat from academic skills. There are a number of intercultural cases available in textbooks and collections (Yu, 2012, pp. 173-174), and it is possible to adjust them to the needs of the assessor. The weakness is the same as that of dialogue-based assessment: the need for a qualified facilitator/assessor. A variation on case studies, situation-judgment tests, provide an abbreviated case description and request responses to specific questions, often selections from a multiple-choice list. They represent the most structured and therefore easiest to assess form of both critical incident analysis and performance in a contrived situation. However, there are validity issues (Griffith, et al., pp.13-14)

\section{Performance in Real or Contrived Situ- ations}

The value of observing real performance is obvious, as "It is axiomatic in personnel selection that past behavior is the best predictor of future behavior" (Mesmer-Magnus \& Viswesvaran, 2008, p. 185). This approach provides past behavior to assess. However, depending on circumstances, real intercultural interactions may be hard to come by before the expatriate is abroad. Role play and to an even greater degree computer-based simulations reduce the realism of this potentially highly valid type of assessment. Furthermore, they require significant time, money, and labor to generate (Yu, 2012, pp. 181-182). Nevertheless, they are in use in organizations where the requirements justify the expense, as in some military occupations (Griffith et al., 2016, pp. 14-15).

Two potentially telling methods of performance observation are the 360 degree assessment and the host family assessment. In 360 degree assessments, people who interact with the subject (supervisors, peers, and subordinates, for example) rate the subject on constituent attributes or skills of intercultural competence (Cartwright, 2016; Fantini, 2006, Appendix F). Host family assessments are similar, but specifically for use when a subject spends time abroad in a host family's home. For the purposes this review is designed to support, the expatriate selection may already have been made at that point.

The 360 degree and host family approaches are often an adaptation of self-report instruments and can be similarly quantitative. However, they eliminate self-reporting issues. Their most obvious potential weaknesses derive from the observers themselves. Their observation skills and the quality and quantity of their observations can vary widely; that variation can affect the validity and reliability of the assessment (Dervin, 2010, p. 9). Even so, the observers have observed the subject's real-life behavior, unbiased by any knowledge of an assessment taking place, and their insight can be revealing.

\section{Meta-Review of Assessment In- struments}

This section will integrate other researchers' reviews of the most prevalent methods of assessment, which are instruments. The criteria will be validity, reliability, and cost in time, money and labor. To meet the standard for inclusion, each instrument had to meet three criteria. First, it had to have been compared against an array of at least four others in at least three peer-reviewed articles. The process for finding those articles and other supporting sources is described in the "Literature Search Procedures" section below.

Second, it had to assess a construct that is both of sufficient scope and roughly similar to the aforementioned framework for intercultural competence. In other words, the measured construct must include cognitive, motivational, and conative dimensions, with multiple components for each dimension. The lone exception to this rule is the Intercultural Development Inventory (IDI). Its wide usage, especially in selection for international assignments, necessitated its inclusion. The IDI derives from the Development Model of Intercultural Sensitivity, or DMIS, a construct which is unique in that it focuses on stages of development (Stuart, 2008, p. 182; Paige, 2004, p. 99; Wang \& Kulich, 2015, p. 39). However, to identify the subject's DMIS stage, the IDI measures knowledge, skills, behavior, and other personal factors (KSAOs) just like other instruments in this review (Bücker \& Poutsma, 2010, p. 273).

Third, the instruments must have the support of a generally successful body of validity and reliability testing. "Validity indicates whether the test measures what it says it does and relates directly to the test's purpose. Reliability tells how well the instrument produces consistent results each time it is used. Tests with high validity and reliability factors are obviously desirable" (Fantini, 2009, p. 475).

Validity, however, has multiple aspects (see Table 1 below). Content validity is often the type of validity researchers check for initially. It is the extent to which the items in the test appear to represent what the test is supposed to measure. This means how it appears to subject matter experts, not how it appears to laymen, which is face validity. Content validity is somewhat subjective because it depends upon general agreement regarding the meaning of the trait being measured (Pennington, 2018, p. 37; Sercu, 2004, p. 79). In 2013, Matsumoto and Hwang 
determined that evaluations of content validity for instruments measuring intercultural competence should seek to answer the following questions (Matsumoto \& Hwang, 2013, p. 851):

1 . Were the desirable outcomes clearly identified and defined?

2 . Were the target cultures clearly identified?

3. Were the knowledge, skills, abilities, and other characteristics (KSAOs) associated with the desirable outcomes in the target cultures clearly defined?

4. Did the KSAOs exhaust the possibilities of all KSAOs that could potentially be predictive of the desirable outcomes?

5. Did the generated item pools exhaust the possible universe of measurement for each $\mathrm{KSAO}$ ?

Construct validity is narrower than content validity. It is the degree to which the test measures the construct it is supposed to measure (Sercu, 2004, p. 79). Construct validity has multiple components, including structural validity, convergent validity, and divergent validity (Lieberman \& Garnst, 2015, p. 18). Structural validity is "the extent to which items designed to measure a particular factor (i.e., latent construct) actually do so" (Byrne, 2000, p. 99) or the extent to which the scores of an instrument adequately reflect "the dimensionality of the construct to be measured" (Mokkink et al., 2010, p. 743). For our purposes, structural validity describes how well the instrument measures all the dimensions of the intercultural competence construct it is designed to measure. Convergent validity shows that the instrument is measuring what it is supposed to measure by demonstrating correlations with measures of related constructs. Divergent validity is also known as dis- criminant validity. It shows that the instrument is not also measuring something else by demonstrating modest correlations with concepts distinct from intercultural competence (Lieberman \& Garnst, 2015, p. 18; Matsumoto \& Hwang, 2013, p. 851).

Ecological validity is essentially correlation with real world outcomes (Lieberman \& Garnst, 2015, p. 18; Matsumoto \& Hwang, 2013, pp. 851-852). Its two most important sub-components for the purposes this article supports (selection and preparation of assigned expatriates) are concurrent and predictive validity. Concurrent validity occurs when that correlation is established at the same time as the assessment (e.g., someone with demonstrated cross-cultural interaction success doing well on the corresponding portions of the assessment). Predictive validity for this field is the ability to reliably predict performance in intercultural settings (Bücker \& Poutsma, 2010, p. 277; Sercu, 2004, p .79). Unfortunately, thoroughly testing the predictive validity of intercultural competence requires consistent performance measurement criteria and ideally a longitudinal study (Griffith et al., 2016, p. 26). Thus, predictive validity has been tested less often than other aspects.

Reliability also has multiple aspects. Two that are most relevant to this article are internal reliability (or internal consistency) measured by Cronbach's Alpha, and test-retest reliability. Internal reliability means, for our purposes, that items on a survey instrument intended to measure the same aspect of intercultural competence receive similar responses. Test-retest reliability is what Fantini addressed above - consistent results across multiple uses of an instrument on a specific subject, assuming all else remains the same. For example, if a subject takes a course in

Table 1. Aspects of Assessment Validity

\begin{tabular}{|l|l|}
\hline Content validity & $\begin{array}{l}\text { Extent to which the items in the test appear to represent what the test is supposed to } \\
\text { measure - to subject matter experts }\end{array}$ \\
\hline Face validity & $\begin{array}{l}\text { Extent to which the items in the test appear to represent what the test is supposed to } \\
\text { measure - to laymen }\end{array}$ \\
\hline Content validity & Degree to which the test measures the construct it is supposed to measure \\
\hline $\begin{array}{l}\text { Structural } \\
\text { validity }\end{array}$ & $\begin{array}{l}\text { Extent to which items measure the particular factor (latent construct) they were de- } \\
\text { signed to }\end{array}$ \\
\hline $\begin{array}{l}\text { Convergent } \\
\text { validity }\end{array}$ & Demonstrates correlations with measures of related constructs \\
\hline $\begin{array}{l}\text { Divergent } \\
\text { validity }\end{array}$ & $\begin{array}{l}\text { Demonstrates modest correlations with concepts distinct from the one being mea- } \\
\text { sured }\end{array}$ \\
\hline $\begin{array}{l}\text { Ecological } \\
\text { validity }\end{array}$ & Correlation with real world outcomes \\
\hline - Concurrent & Correlation established at the same time as assessment (describes current state) \\
\hline - Predictive & $\begin{array}{l}\text { Correlation between assessment results and future outcomes (describes future perfor- } \\
\text { mance) }\end{array}$ \\
\hline
\end{tabular}


cross-cultural communications or spends a semester abroad between two survey iterations, one could expect results to differ. A third category, parallel forms reliability, measures correlation between two different (but ostensibly equivalent) versions of an instrument. It is particularly relevant to this topic when different versions of an instrument are prepared for different languages and cultures.

\section{Literature Search Procedures}

The meta-review in this article required relatively recent sources that had compared multiple cross-cultural assessment instruments. This author knew that such articles existed because the Lieberman and Garnst article (2015) in the bibliography (found in prior research) identified one (Matsumoto \& Hwang, 2013). The Deardorff and Fantini sources had also already arisen from previous research. To find such sources, I used University of South Florida Library access to ABI/INFORM Global, to simultaneously search anywhere within peer-reviewed, English language articles from the last ten years for combinations of the following terms:

- Intercultural competence

- Cross-cultural competence

- Intercultural adaptability

- Cross-cultural adaptability

- Cultural intelligence

- Assessment

- Measurement

- Evaluation

- Instrument

The search returned 173 articles. Within those, I searched for "validity" and received 57 results, then searched within those returns for "reliability" and received 37 results. The results were unsatisfactory. So subsequent searches modified the terms - adding "validity" to the initial search terms, limiting years to the last two, then narrowing the search field to just the abstract. That yielded many studies on the cross-cultural validity of instruments measuring completely different competencies. Then, I simultaneously narrowed the search field to the title and the abstract and broadened the search terms to include variations of the original terms:

Title (intercultural OR cross-cultural OR global) AND

Abstract (assessment OR assessing OR measurement OR measuring)

AND

Title (competence OR competency OR competencies OR awareness OR sensitivity OR adaptability OR adjustment)

AND

Abstract (instruments OR instrumentation OR tools OR test OR tests)

AND

Abstract (review OR investigation)
This actually yielded relevant sources, so the next search again expanded the terms (intercultural, cross-cultural, or global, asses ${ }^{\star}$, instrumen ${ }^{\star}$, test ${ }^{\star}$ ) and narrowed the field to the title. The results from these final two searches, the bibliographies of those results, and sources identified through previous research, provided sufficient instrument review sources to conduct a meta-review.

In addition to ABI/INFORM, Google Scholar and ProQuest enabled download. For specifics on individual instruments and their use, I referenced articles on that instrument alone as well as the work of those who have used it commercially. The end result was six peer-reviewed comparative reviews of intercultural competence instruments (including four journal articles and two chapters from graduate-level texts; see Table 2 below), four non-peer-reviewed inventories of instruments, and a host of supporting sources.

\section{Cross-Cultural Adaptability Inventory (CCAI)}

The first instrument under review is the CCAI, which Colleen Kelley and Judith Meyers developed in 1987. It is a 50 -item survey using a five-point Likert scale to assess four components of cross-cultural adaptability - Emotional Resilience, Flexibility/Openness, Perceptual Acuity, and Personal Autonomy. These four factors also function as sub-scales. The CCAI can be used in either self-report mode or with three selected observers as a $360^{\circ}$ feedback instrument (Stuart, 2008, p. 178; Cartwright, 2016, p. 33; Perry \& Southwell, 2011, pp. 461-462; Matsumoto \& Hwang, 2013, p. 854; Paige, 2004, p. 114; Griffith et al., 2016, p. 8; Bücker \& Poutsma, 2010, p. 283)

Kelley and Meyers designed the CCAI specifically to measure a person's ability to adapt to other cultures. It is in wide use in both academic and workplace environments for data-based training, program evaluation (pre- and post-testing), and consultation. Kelley, Meyers, and other trainers who use the CCAI claim that it helps learners understand and develop the components of intercultural competence. To facilitate that use, there is a follow-up training tool called the CCAI Action Planning Guide and other supporting material. Most relevant to this review, users recommend the CCAI as a self-selection instrument for international assignments - i.e., helping a candidate determine whether she or he wants to work abroad - or as part of a battery of testing for selection (Stuart, 2008, p. 178; Cartwright, 2016, pp. 33-34; Perry \& Southwell, 2011, pp. 461-462; Paige, 2004, pp. 114-115).

The CCAI's early development, simplicity and low cost have all contributed to its extensive use. Administrators need no certification (Stuart, 2008, p. 
Table 2. Academic Reviews of Intercultural Competence Assessment Instruments

\begin{tabular}{|c|c|c|c|}
\hline $\begin{array}{l}\text { Author(s) } \\
\text { and Date }\end{array}$ & $\begin{array}{c}\text { \# of Instruments } \\
\text { Evaluated }\end{array}$ & Intent & Aspects Covered \\
\hline Stuart, 2008 & $\begin{array}{l}10 \text { for selection, } 5 \text { for de- } \\
\text { velopment }\end{array}$ & $\begin{array}{l}\text { Identify, distinguish be- } \\
\text { tween, and describe instru- } \\
\text { ments useful for selection } \\
\text { and training }\end{array}$ & $\begin{array}{l}\text { General description of each } \\
\text { assessment, its utility, and its } \\
\text { unique features }\end{array}$ \\
\hline $\begin{array}{l}\text { Bücker and } \\
\text { Poutsma, } \\
2010\end{array}$ & $\begin{array}{l}23 \text {, but } 8 \text { receive greater } \\
\text { focus }\end{array}$ & $\begin{array}{l}\text { Design a framework for } \\
\text { systematically assessing in- } \\
\text { struments designed to mea- } \\
\text { sure Global Management } \\
\text { Compe- tencies (GMC); } \\
\text { select the most useful for } \\
\text { that purpose }\end{array}$ & $\begin{array}{l}\text { Purpose } \\
\text { Composition } \\
\text { Number of Items } \\
\text { Samples } \\
\text { Language } \\
\text { Reliability and validity } \\
\text { Cross-cultural equivalence } \\
\text { (For selected 8) Nature of } \\
\text { measurement and compo- } \\
\text { nent of Global Management } \\
\text { Competencies }\end{array}$ \\
\hline $\begin{array}{l}\text { Perry and } \\
\text { Southwell, } \\
2011\end{array}$ & 4 & $\begin{array}{l}\text { Define intercultural com- } \\
\text { petence, then describe how } \\
\text { to develop it and how to } \\
\text { measure it }\end{array}$ & $\begin{array}{l}\text { General description of each } \\
\text { assessment and the con- } \\
\text { struct on which it is based, } \\
\text { its utility, and other salient } \\
\text { findings from research }\end{array}$ \\
\hline Paige, 2004 & $\begin{array}{l}9 \text { (includes those measur- } \\
\text { ing intercultural develop- } \\
\text { ment; cultural adjustment, } \\
\text { culture shock, and cultural } \\
\text { adaptation; and intercul- } \\
\text { tural and multicultural } \\
\text { competence) }\end{array}$ & $\begin{array}{l}\text { Describe utility of instru- } \\
\text { ments for support to inter- } \\
\text { cultural training }\end{array}$ & $\begin{array}{l}\text { Overview } \\
\text { Purposes for Intercultural } \\
\text { Training } \\
\text { Key Concepts } \\
\text { Items } \\
\text { Reliability and Validity } \\
\text { Evidence of Use in Training } \\
\text { Availability, Training Re- } \\
\text { quirements, and Scoring } \\
\text { Requirements }\end{array}$ \\
\hline $\begin{array}{l}\text { Matsumoto } \\
\text { and Hwang, } \\
2013\end{array}$ & 10 & $\begin{array}{l}\text { "provide a comprehensive } \\
\text { review of the available tests } \\
\text { of "cross-cultural compe- } \\
\text { tence" }\end{array}$ & $\begin{array}{l}\text { Evidence for ecological } \\
\text { validity, including: } \\
\text { Validity and reliability of the } \\
\text { criterion variables } \\
\text { Number and breadth of } \\
\text { cross-cultural samples } \\
\text { Mixed methodologies } \\
\text { Time of assessment } \\
\text { Incremental validity }\end{array}$ \\
\hline $\begin{array}{l}\text { Griffith et al., } \\
2016\end{array}$ & $\begin{array}{l}32 \text { ( } 30 \text { for validity and } \\
\text { reliability) }\end{array}$ & $\begin{array}{l}\text { "explore the possibility and } \\
\text { utility of assessing [intercul- } \\
\text { tural competence] for stu- } \\
\text { dents in higher education" }\end{array}$ & $\begin{array}{l}\text { Format } \\
\text { Delivery } \\
\text { Forms and items } \\
\text { Themes/topics } \\
\text { Reliability and validity }\end{array}$ \\
\hline
\end{tabular}


178). The inventory itself takes twenty minutes to complete. An online version of the CCAI is available for $\$ 26$, but requires a $\$ 199$ one-year subscription to an online assessment center. Other pricing models are available for paper versions or with an intercultural training packages intended to help participants "explore their own cultural identity and learn to improve their interactions with other cultures" (http:// ccaiassess.com/product_pricing.html ${ }_{2}$ https://hrdqstore.com/collections/online-assessments/products/cross-cultural-adaptability, accessed 21 March 2021).

Kelley and Meyers developed the instrument in 1987 based on the literature then available regarding cross-cultural adaptability. To establish validity, they submitted the items to a panel of expert judges and used factor analysis (Paige, 2004, pp. 114-115). On the four subscales listed above, reliability (internal consistency) coefficients range from as high as .82 to as low as .68 - slightly below the usual .70 cutoff for acceptability. An unreliable subscale assessment can degrade the utility for tailored feedback and training plan development. In other words, if measurement of one component factor is unreliable, it could affect how well the assessment can inform the participant on his performance and guide training to improve in that area.

The overall scale rates an impressive .90 reliability coefficient. Two studies found poor evidence for the four-factor structure, and one of those specifically found poor divergent validity between the subscales. The subscales correlated highly with each other, suggesting that they are all measuring a unitary dimension of intercultural adaptability (Paige, 2004, pp. 114-115; Griffith et al., 2016, pp. 15-16, 21-23; Stuart, 2008, p. 178; Perry \& Southwell, 2011, p. 462; Matsumoto \& Hwang, 2013, p. 854).

Research shows some evidence of convergence between the CCAI and the Big Five personality traits of extroversion, agreeableness, conscientiousness, emotional stability, and openness to new experiences (Griffith et al., 2016, pp. 16, 21). One study found significantly higher scores on the CCAI among graduate students who had received intercultural competence training compared to those who had not, suggesting potential predictive validity (Matsumoto \& Hwang, 2013, p. 854).

\section{Multicultural Personality Question- naire (MPQ)}

Dutch researchers Karen I. Van der Zee and Jan Pieter Van Oudenhoven developed the self-report MPQ in 1998 and revised it two years later. The number of items vary in different versions - originally 78 , then 91 , and most recently 40 . All use a five-point Likert scale. Of the five traits the MPQ measures, three - cultural empathy, open-mindedness, and social initiative - have demonstrated the potential for improvement after training or other relevant life experience. The other two, emotional stability and flexibility, are more stable. The MPQ is designed primarily for self-assessment, but may be used to assess risk in international assignment selection, as it may predict how well a person will adjust to another culture (Stuart, 2008, pp. 180-181; Bücker \& Poutsma, 2010, pp. 274, 288; Matsumoto \& Hwang, 2013, pp. 861-862; Griffith et al., 2016, p. 9; Van der Zee et al., 2013, p. 121; Mello, 2014, p. 376; Tamas Consultants. n.d.).

The MPQ is well-validated. It has demonstrated internal reliability at both subscale and scale level as well as construct, content, concurrent, and predictive validity, even across widely varying cultures. In fact, its validity in predicting adjustment and adaptation exceeds demographic variables, personality measures, standard intelligence measures, and the Cultural Intelligence Scale (CQS) described below (Bücker \& Poutsma, 2010, pp. 274, 288; Matsumoto \& Hwang, 2013, p. 861-868; Griffith et al., 2016, p. 18). As of this writing, it costs $€ 60$, or approximately $\$ 72$ (H. van der Heijden, personal communication, 6 August 2019). It takes ten to fifteen minutes to complete online, and immediately generates a report describing the meaning of each subscale score. Consultants may offer more detailed feedback (Tamas Consultants. n.d.; KIT Royal Tropical Institute, n.d.;).

\section{Intercultural Adjustment Potential Scale (ICAPS)}

The ICAPS is a 55-item self-report online survey developed by David Matsumoto and colleagues in 2001. Its items use a seven-point Likert scale to measure intercultural competence by assessing four psychological skills. These include emotional regulation, openness, flexibility, and critical thinking. It produces one overall score and a score for each of the four assessed skills (Griffith et al., p.8; Bücker \& Poutsma, 2010, pp. 273, 285; Matsumoto \& Hwang, 2013, p. 863; Cartwright, 2016, p. 36). According to Matsumoto, the ICAPS literally measures the capacity to adjust, looking at both personality traits and metacognitive processing (Bücker \& Poutsma, 2010, p. 275). Unlike some instruments, the ICAPS is designed to account for cultural equivalence, specifically between Japanese and English-speaking cultures (Bücker \& Poutsma, 2010, p. 285).

The ICAPS has marginal construct validity overall, some convergent and divergent validities, adequate content validity, and most importantly, extensive concurrent and predictive ecological validity (Griffith et al., 2016, p. 16; Matsumoto \& Hwang, 2013, pp. 857-868; Bücker \& Poutsma, 2010, p. 285). Like the MPQ, it has shown incremental predictive validity over standard personality and intelligence scales. It has also demonstrated adequate internal 
and test-retest reliability, as well as reliability across other languages (Matsumoto \& Hwang, 2013, pp. 864-865, 867-868; Bücker \& Poutsma, 2010, p. 285). It is available from Humintell for $\$ 25$ as seen on https://www.humintell.com/product/icaps-intercultural-adjustment-potential-scale/, accessed on 21 March 2021.

\section{Cultural Intelligence Scale (CQS)}

Cultural intelligence (CQ) is a construct with motivational, conative, and cognitive aspects. The term refers to a set of capabilities considered to be important for successful intercultural interaction. Dr. Soon Ang and colleagues defined CQ in articles beginning in 2003 and subsequently developed the CQS in 2007. The CQS is a 20 -item, online self-assessment survey using seven-point Likert scales to examine four factors and their interrelationships: strategy, knowledge, motivation, and behavior. The CQS has been tested across multiple cultures, and there is a version for 360 degree assessment (Cartwright, 2016, p.34; Griffith et al., 2016, p. 8; Bücker \& Poutsma, 2010, pp. 273-274, 284; Matsumoto \& Hwang, 2013, pp. 855, 865, 868). More recently, The Cultural Intelligence Center developed a 39-item version of the instrument, but the data supporting this article derives from the 20-item survey.

In testing, the CQS has shown structural, convergent, and divergent validity (Griffith et al., 2016, p. 17; Matsumoto \& Hwang, 2013, pp. 856) as well as adequate content validity and strong concurrent and predictive validity (Matsumoto \& Hwang, 2013, pp. 856, 863-868). Like the MPQ and ICAPS, it has incremental predictive validity over personality factors and intelligence. It has also proven reliable (Griffith et al., 2016, p. 17; Bücker \& Poutsma, 2010, p. 284; Matsumoto \& Hwang, 2013, pp. 856, 868).

The self-report form of the CQS is available for $\$ 60$ at the Cultural Intelligence Center (https://culturalq. $\mathrm{com} /$, accessed 6 July 2019). Upon completion, the respondent receives an explanatory report, which includes ratings and norms for the four cultural intelligence capabilities and 13 sub-dimensions. It also includes the respondent's cultural value preferences and the shell of a development and action plan for use in further developing cultural intelligence. If the subject uses both the self-report and the 360 degree assessment, the resulting report will compare the consolidated responses of others against the subject's own.

\section{Intercultural Development Inventory (IDI)}

The reader should first note that the authors of two of the primary meta-review sources, R. Michael Paige and Douglas Stuart, employ the IDI commercially. They have also provided positive testimonials on idiinventory.com, the website for the IDI Limited
Liability Company, which is a component of Hammer Holdings, Incorporated (The roadmap to intercultural competence using the IDI: success stories: testimonials, 2019).

Mitchell Hammer and Milton J. Bennett developed the IDI in the mid-1990s using Bennett's Development Model of Intercultural Sensitivity (DMIS) as the foundational construct. The IDI is a self-report survey instrument. It uses 50 five-point Likert scale items to place respondents at one of five (formerly six) stages of an intercultural development continuum. The stages are denial, defense (or polarization), minimization, acceptance, and adaptation. The continuum is really measuring how the respondents view, understand, and react to cultural differences (Stuart, 2008, p. 182; Cartwright, 2016, p.37; Perry \& Southwell, 2011, p. 460; Matsumoto \& Hwang, 2013, p. 860; Paige, 2004, p. 99; Griffith et al., 2016, p. 8). This is essentially metacognition and cognitive processing (Bücker \& Poutsma, 2010, pp. 273-274).

Organizations currently use the IDI in selection for cross-cultural assignments, but also for assessment of training effectiveness and of intercultural competence among groups, such as audiences or leadership teams. The IDI also supports training and developmental planning by helping identify the most effective kind of intervention for increasing intercultural competence (Stuart, 2008, p. 182; Cartwright, 2016, p. 37; Perry \& Southwell, 2011, p. 460; Paige, 2004, pp. 88, 99).

However, only a trained interpreter, certified through a three-day seminar, can score the IDI and thus generate the detailed feedback necessary for that degree of utility (Paige, 2004, pp. 91, 100; Stuart, 2008, p. 182). That is not the only identified drawback to the IDI. Perry and Southwell argue that the linear, fivestage continuum oversimplifies the process of developing intercultural competence, especially since the continuum by itself (i.e., without the interpreter) provides no detail of the dimensions measured (2011, p. 461).

Studies have found the IDI to have adequate content validity and high internal reliability (Matsumoto \& Hwang, 2013, pp .860, 863; Paige, 2004, p. 99; Griffith et al., 2016, p. 17). It has also proven resistant to bias due to gender, age, education, or social desirability. (Griffith et al., 2016, p. 17; Paige, 2004, p. 91). Studies have shown that IDI scores correlate positively with "worldmindedness," degree of prior intercultural experience, number of friends from other cultures, and satisfaction with intercultural experiences. IDI correlates negatively with intercultural anxiety. These results strongly support IDI's construct validity and to a lesser degree, its ecological validity (Matsumoto \& Hwang, 2013, p. 860; Paige, 2004, p. 99; Griffith et al., 2016, pp. 21-22). Studies on the IDI's utility for training assessment have had mixed results (Matsumoto \& Hwang, 2013, p.860), 
Table 3. Comparison of Intercultural Competence Assessment Instruments

\begin{tabular}{|c|c|c|c|c|c|}
\hline Instrument & Features & Costs & $\begin{array}{l}\text { Training } \\
\text { Requirements }\end{array}$ & Advantages & Disadvantages \\
\hline $\begin{array}{l}\text { Cross-Cultural } \\
\text { Adaptabili- } \\
\text { ty Inventory } \\
\text { (CCAI) }\end{array}$ & $\begin{array}{l}\text { - } 50 \text {-item survey } \\
\text { - In wide use } \\
\text { - Best used for } \\
\text { self-selection } \\
\text { or as part of a } \\
\text { battery }\end{array}$ & $\begin{array}{l}\$ 98 \text { for up to } \\
5 \text { people (pa- } \\
\text { per); online } \\
\text { version } \$ 26, \\
\text { but requires } \\
\$ 199 \text { sub- } \\
\text { scription to } \\
\text { other services }\end{array}$ & None & $\begin{array}{l}\text { - Highly reliable } \\
\text { as an overall } \\
\text { scale } \\
\text { - Can be used } \\
\text { with a fol- } \\
\text { low-on tool } \\
\text { for tailored } \\
\text { training }\end{array}$ & $\begin{array}{l}\text { - Poor divergent } \\
\text { validity for } \\
\text { component } \\
\text { subscales, so } \\
\text { may really be } \\
\text { measuring } \\
\text { cross-cultural } \\
\text { adaptability as } \\
\text { a whole }\end{array}$ \\
\hline $\begin{array}{l}\text { Multicultural } \\
\text { Personality } \\
\text { Questionnaire } \\
\text { (MPQ) }\end{array}$ & $\begin{array}{l}\text { - } 40 \text {-item survey } \\
\text { (or more, in } \\
\text { older versions) }\end{array}$ & $\begin{array}{l}\sim \$ 72 \text { (actual } \\
\text { price is in } \\
\text { Euros) }\end{array}$ & None & $\begin{array}{l}\text { - High reliabili- } \\
\text { ty and validity } \\
\text { across multiple } \\
\text { aspects and } \\
\text { cultures }\end{array}$ & None identified \\
\hline $\begin{array}{l}\text { Intercultural } \\
\text { Adjustment } \\
\text { Potential Scale } \\
\text { (ICAPS) }\end{array}$ & $\begin{array}{l}\text { - } 55 \text {-item survey } \\
\text { - measures } \\
\text { capacity to ad- } \\
\text { just, looking at } \\
\text { both person- } \\
\text { ality traits and } \\
\text { metacognitive } \\
\text { processing }\end{array}$ & $\$ 25$ & None & \begin{tabular}{|l} 
- Valid and \\
reliable across \\
multiple mea- \\
sures (includ- \\
ing predictive \\
reliability)
\end{tabular} & None identified \\
\hline $\begin{array}{l}\text { Cultural Intel- } \\
\text { ligence Scale } \\
\text { (CQS) }\end{array}$ & $\begin{array}{l}\text { - 20-item, on- } \\
\text { line self-assess- } \\
\text { ment survey } \\
\text { - 39-item and } \\
360 \text { degree } \\
\text { versions avail- } \\
\text { able }\end{array}$ & $\$ 60$ & None & \begin{tabular}{|l} 
- Reliable; valid \\
across multi- \\
ple measures \\
(especially \\
predictive \\
reliability) \\
- Explanatory \\
report upon \\
completion
\end{tabular} & None identified \\
\hline $\begin{array}{l}\text { Intercultural } \\
\text { Development } \\
\text { Inventory } \\
\text { (IDI) }\end{array}$ & $\begin{array}{l}\text { - 50-item survey } \\
\text { - Places respon- } \\
\text { dents at one of } \\
\text { five stages of } \\
\text { an intercultur- } \\
\text { al development } \\
\text { continuum } \\
\text { measuring how } \\
\text { the respon- } \\
\text { dents view, } \\
\text { understand, } \\
\text { and react to } \\
\text { cultural differ- } \\
\text { ences }\end{array}$ & $\$ 12-\$ 30$ & $\begin{array}{l}\text { Three-day } \\
\text { seminar quali- } \\
\text { fying someone } \\
\text { to administer } \\
\text { and score the } \\
\text { inventory } \\
\text { costs between } \\
\$ 1600 \text { and } \\
\$ 2000\end{array}$ & $\begin{array}{l}\text { - Useful for } \\
\text { training devel- } \\
\text { opment } \\
\text { - Adequate con- } \\
\text { tent validity; } \\
\text { high internal } \\
\text { reliability; } \\
\text { bias-resistant } \\
\text { - Correlations } \\
\text { with other } \\
\text { measures sup- } \\
\text { port construct } \\
\text { validity and to } \\
\text { a lesser degree, } \\
\text { ecological } \\
\text { validity }\end{array}$ & $\begin{array}{l}\text { Full utility for } \\
\text { training requires } \\
\text { administrator }\end{array}$ \\
\hline
\end{tabular}


but other factors in the training curriculum or training audience may have contributed.

According to idiinventory.com, an individual can take an IDI for \$12-\$30 and have unlimited access to reports. However, the three-day seminar qualifying someone to administer and score the inventory costs between $\$ 1600$ and $\$ 2000$. Prices vary depending on whether the purchaser represents an educational institution, a non-profit, or another organization. Consultants specializing in intercultural training and assessment will provide price quotes on request for administering and scoring the IDI. Organizations choosing to use the IDI are obliged to compare those fees with the costs of developing the capability to do so in-house.

\section{Honorable Mentions}

Three instruments met the criterion for inclusion in sufficient scholarly comparisons, but lacked scope, testing or a body of generally successful testing. Those three are the Intercultural Sensitivity Inventory (ICSI), the Intercultural Sensitivity Scale (ISS), and the Behavioural Assessment Scale for Intercultural Competence (BASIC). They warrant mention, if not full review.

Like most of the instruments reviewed herein, the ICSI is Likert scale-based self-report survey. However, it is unique in that it is only measuring two personality traits (flexibility and open-mindedness) and one cultural value orientation (individualism versus collectivism). The ICSI's internal reliability is high. However, its ecological validity testing is limited, and the results of that testing are mixed. It is primarily used in training (Cartwright, 2016, p. 38; Bücker \& Poutsma, 2010, pp. 275, 286; Matsumoto \& Hwang, 2013, pp. 859-866; Paige, 2004, p. 100; Griffith et al., 2016, pp. 11, 20).

However, given the narrow measurement scope of the ICSI, the fact that it demonstrated even mixed validity indicates that the aspects its creators (Bhawuk and Brislin) chose to measure are genuinely critical. Bhawuk and Brislin claim that "a good approach to measuring intercultural sensitivity is to determine people's knowledge about and willingness to change behaviours related to the individualistic or collectivistic background of others" (Bhawuk \& Brislin, 1992, p. 418). They also determined that three years of experience in a foreign culture increases intercultural sensitivity, and a willingness to eat food from diverse cultures signals such sensitivity (Bücker \& Poutsma, 2010, p. 275). Such intriguing findings indicate that their research merits further scholarly attention.

True to its name, the ISS measures intercultural sensitivity, which its creators (Chen and Starosta, 2000) limit to the affective aspect of intercultural competence, excluding behavior or skills (Perry \& Southwell, 2011, pp. 453, 461). It is yet another Likert scale self-report survey for which testing has demonstrated high internal reliability overall, but in this case, not every sub-scale has done so. Only two studies support its ecological validity. Among U.S. students, they show correlations with attitudes toward intercultural communication and intercultural decision quality (Griffith et al., 2016, pp. 8, 17; Matsumoto \& Hwang, 2013, pp. 861-866; Perry \& Southwell, 2011, p. 461). In sum, this is another promising instrument of narrow scope and limited research support.

The BASIC is noteworthy in that it is the only purely qualitative instrument in this meta-review, despite the fact that researchers lament both the need for more qualitative measurement tools (Matsumoto \& Hwang, 2013, p. 868) and the importance of mixed methods of assessment (Deardorff, 2006, p. 250; Fantini, 2009, p. 465). Researchers Koester and Olebe developed the BASIC by revising a previous assessment tool known as the Intercultural Behavioral Assessment (IBA) (Matsumoto \& Hwang, 2013, pp. 856, 857). The IBA was designed to be easily administered by untrained observers (Matsumoto \& Hwang, 2013, p. 866). The BASIC similarly relies on peer ratings and a Likert scale that is unique among those listed in this meta-review; it uses a four-point scale and behavioral descriptions (Griffith et al., 2016, pp.10, 12). Andrea Graf and Lynn K. Harland suggest that the BASIC is most useful for assessing "the degree to which a person tends to judge and interact with people from different cultures in a respectful, empathetic and non-evaluative way" (2005, p. 57).

There is conflicting reporting on the internal reliability of the overall BASIC scale, and it has significant construct and content validity issues (Matsumoto \& Hwang, 2013, pp. 857, 863-864; Griffith et al., 2016, pp. 15, 19) There is some evidence on the BASIC's ecological validity, but each of the three studies that found such evidence was extremely limited in either sample or scope (Matsumoto \& Hwang, 2013, pp. 865-866)

In addition to these, some commercially exploited instruments (Bücker \& Poutsma, 2010, p. 272) are barely mentioned in academic reviews because they are not easily accessible to researchers. Among these, three stand out as having significant suitability for selection of overseas assignees and high credibility overall: the Self-Assessment for Global Endeavors (SAGE); the Tucker Assessment Profile (TAP, a redevelopment of the Overseas Assignment Inventory, or OAI); and the Global Competencies Inventory (GCI).

The SAGE is a three-part instrument developed by well-known researcher Paula Caligiuri. The first two sections assess personality traits and motivation of both an expatriate candidate and a partner with whom he or she intends to travel. The third section is not for assessment. It is an aid to facilitate 
family conversation about an assignment abroad. The SAGE is designed to aid self-selection, but the results can also shape a bespoke training program (Stuart, 2008, p. 181; IOR Global Services, p.3).

The GCI and the TAP also have strong pedigrees, also support training development, and claim greater compatibility with formal human resources assessment than the SAGE. All three have an online survey component, but the GCI and the TAP each require a conversation with a trained facilitator - for debriefing in the case of the GCI, and for a behavioral assessment interview for the TAP. The TAP interview functions as a qualitative, dialogue-based assessment that meets the recommendation to use mixed measures. Purveyors of these three tools tout their validity and reliability. They offer documentation of those claims upon request (Stuart, 2008, p. 181; Griffith et al., pp. 8, 15, 17, 21; IOR Global Services, p. 3).

The survey component of these instruments seems to offer little that is not available from those reviewed in more detail above. It is more useful to view them as part of the suite of tools offered by global relocation and talent development service providers. These companies offer assessment, cultural and language training, consultation, and repatriation support to individuals, families, and corporations confronted with the challenges of international assignments. Examples include Aperian Global, Kozai Group, IOR Global Services, and Tucker International, among others (Cartwright, 2016).

\section{Conclusions, Recommendations, and Learning More}

Technical skills are often necessary for an expatriate position, but they are far from sufficient. Sending an employee to work abroad is a decision that can yield high rewards, but it also comes at high risk. The most important conclusion of this review is that it is possible to significantly reduce that risk, and to do so very inexpensively.

Clearly, there are many ways to identify candidates for international assignment and assess their intercultural competence. The overview and the meta-review above considered validity, reliability, utility for the selection process, cost in time and money, and ease of use. Some require too much time and expertise to be cost-effective outside academic settings, such as works of creative self-expression. Self-assessment instruments are at the opposite end of the spectrum for ease of use, but additional assessments using outside observers and qualitative methods should be employed to corroborate their findings.

Other important factors in expatriate selection include the risks associated with the decision, the resources available, and the magnitude of the requirement in both size and time. Questions regarding the magnitude include, "How big is the candidate pool? How many assignees are required? Is this a one-time requirement, or a recurring one?" If risks and resources are low, an organization may choose methods that take little time or money but are still likely to be effective. In particular, an organization that is experimenting with overseas assignments perhaps a company in its first joint venture with a foreign firm - may establish a minimal assessment process for use in the near term.

An organization may also attempt to reduce risks by spending more resources on assessments and training. For larger, more enduring requirements, organizations can achieve economy of scale by developing in-house assessments and training expertise. They can also partner with full service international mobility specialists for an even wider array of services. An international news outlet or a multinational sales force may need to send personnel to many different cultures. In such cases, the need for language and culture training specific to each host nation will likely compel some level of outsourcing.

Of the self-report surveys, the MPQ, ICAPS, and CQS demonstrated exceptional validity and reliability within an already select group. They are inexpensive, require no special expertise to administer, and generate self-explanatory reports. However, each one is inadequate as a sole method of assessment, and they may even be inadequate in toto. The consensus of experts recommends not only multiple methods of assessment, but both quantitative and qualitative methods.

The CCAI and CQS each offer 360 degree options which counter the biases associated with self-reporting. Dialogue-based assessments or case study analysis are two qualitative options. Using almost no additional resources, a trained assessor can conduct these assessments in a few hours and complete a report in a few days. Organizations can also use business trips overseas as opportunities to observe performance. Ideally, an expert assessor from the human resources department would travel to perform the observation, but many organizations will not have that option. However, observation by even an untrained observer - especially one with experience in the host culture - may be significantly better than no qualitative assessment at all. For the same reason, the BASIC, despite its validity issues, is another qualitative option.

In addition to formal assessments of intercultural competence, there are other indicators that correlate with successes in international assignments. General mental ability (IQ) is one, perhaps in part because intelligence assists in navigating complexity. Prior successful experience overseas also correlates consistently with subsequent performance, as it indicates both motivation and ability (Mesmer-Magnus \& Viswesvaran, 2008, p. 185). The emotional intelli- 
gence construct (EQ) may overlap with intercultural competence even more significantly than IQ, and recent research has worked to better define the overlap and disambiguate the two (Conrad, 2006; Guntersdorfer \& Golubeva, 2018; Altaras Dimitrijević et al., 2019).

It is worth repeating that any assessment and selection procedure must consider more than professional competence and intercultural competence. The expectations, motivation, requirements, and personal circumstances of the candidate and the candidate's family are also key. A detailed discussion of these factors is beyond the scope of this paper, but they can limit the candidate pool significantly and reduce the assessment requirement. Emerald Publishing's Journal of Global Mobility and SAGE Publications' Essentials of International Human Resource Management are good places to start learning more, but there are many other sources. Global mobility consultants also offer relevant expertise. Some, such as Tucker International, provide instructive content free of charge via their websites.

One effective way to start the conversation is to offer an opportunity for intercultural competence self-assessment. Self-assessment can spark interest in employees who had previously never considered international assignments. They may then explore their options within the organization and discuss them with their families. As part of onboarding, organizations with a significant overseas component can provide new hires one or more of the quick, inexpensive self-report surveys discussed in this paper. Those new hires can choose whether or not to share the results with their employer. In this scenario, the employer would explicitly state that sharing the results is a non-binding way to express interest in learning more about international assignments.

Specific recommendations follow below:

- Organizations that have or anticipate having expatriate requirements should include an intercultural competence self-assessment as part of onboarding. Employees should be free to share the results with the company or not at their own discretion.

- Make an individual or an element within the human resources division responsible for selection, preparation, support, and reintegration of expatriate personnel. Empower them to work directly with the divisions sending employees abroad. Encourage them to develop expertise in global mobility, and give them opportunities to do so. If risk tolerance is low or the workload outstrips capacity, budget for the hiring of global mobility consultants to support them.

- To the best of their abilities, the sending organization, the candidates, and the candidates' families should ensure the following is true:

o The candidates and their families under- stand the circumstances and requirements of life and work abroad in the target position.

- They are intrinsically motivated to take the assignment for reasons other than pressure from the organization.

- They can reasonably expect their physical and psychological health, stage of life, and responsibilities outside work to allow this radical (but temporary) lifestyle change.

- At a minimum, have all candidates complete a self-assessment survey as part of the selection process (preferably the MPQ, ICAPS, or CQS). This assessment will differ from the onboarding assessment in that the results must be reportable for the candidate to continue in the selection process. If possible, conduct the following additional assessments, arranged in order of increasing cost:

○ A 360 degree assessment (CCAI or CQS) to counter self-reporting bias

- A qualitative, dialogue or case study-based assessment by a trained assessor

- A business trip to the target location, followed by feedback on the candidates' performance from trusted personnel there or knowledgeable traveling companions

Future research could examine the validity of these conclusions by comparing the results of an organization's expatriate assignments before and after their implementation.

Expatriate assignments have a tremendous impact on both organizations and individuals, and there are more factors than just assessments, selections, and development affecting their success, such as support, communication, management, and repatriation. Valuable experiential lessons and relevant research findings are available on all these topics, but they must be sought out and applied. Expatriate success garners prodigious opportunities, but the risk of costly failure is high. These facts justify the expenditure of time, money, and attention to get international assignments right.

\section{References}

Altaras Dimitrijević, A., Starčević, J., \& Jolić Marjanović, Z. (2019). Can ability emotional intelligence help explain intercultural effectiveness? Incremental validity and mediation effects of emotional vocabulary in predicting intercultural judgment. International Journal of Intercultural Relations, 69, 102-109. https://doi.org/10.1016/j. ijintrel.2019.01.005

Bhawuk, D. P., \& Brislin, R. (1992). The measurement of intercultural sensitivity using the concepts of individualism and collectivism. International Journal of Intercultural Relations, 16(4), 413-436. 
https://doi.org/10.1016/0147-1767(92)90031-O

Bird, A., Mendenhall, M., Stevens, M. J., \& Oddou, G. (2010). Defining the content domain of intercultural competence for global leaders. Journal of Managerial Psychology, 25(8), 810-828. https:// doi.org/10.1108/02683941011089107

BGRS, AKA Brookfield Global Relocation Services. (2016). Breakthrough to the future of global talent mobility. Global Mobility Trends Survey. Retrieved from http://globalmobilitytrends.bgrs. com/ on 14 August 2018.

Bücker, J., \& Poutsma, E. (2010). How to assess global management competencies: An investigation of existing instruments. Management Revue, 263291. https://doi.org/10.5771/0935-9915-2010-3263

Byrne, B. M. (2000). Structural equation modeling with AMOS : Basic concepts, applications, and programming. Mahwah, N.J.: Psychology Press.

Cantele, M., Groeschke, D., Sandu, O. N., \& Barrett, M. (2015). Assessment of intercultural learning - principles, practices and challenges: A summary of the outcomes of four workshops. Intercultura, 76, 23-24. Retrieved from https://www. academia.edu/28260382/Assessment_of_intercultural_learning_principles_practices_and_ challenges_A_summary_of_the_outcomes_of_four_workshops on 4 February 2018.

Cartwright, C. (2016). Frequently used assessment tools. Handout at the 103rd annual meeting of the Association of American Colleges and Universities (AACU) in San Francisco, CA on 28 January 2017. Linked as discussion handout 2 on https:// www.aacu.org/meetings/annualmeeting/AM17/ resources or directly accessible at https://www. aacu.org/sites/default/files/files/AM17/Cartwright $\% 20$ Handout $\% 202$.pdf.

Chi, R., \& Suthers, D. (2015). Assessing intercultural communication competence as a relational construct using social network analysis. International Journal of Intercultural Relations, 48, 108-119. https://doi.org/10.1016/j.ijintrel.2015.03.011

Collings, D. G., Scullion, H., \& Morley, M. J. (2007). Changing patterns of global staffing in the multinational enterprise: Challenges to the conventional expatriate assignment and emerging alternatives. Journal of World Business, 42(2), 198-213. https://doi.org/10.1016/j.jwb.2007.02.005

Conrad, J. E. (2006). The relationship between emotional intelligence and intercultural sensitivity (Doctoral dissertation, University of North Florida).

Deardorff, D. K. (2011). Assessing intercultural competence. New Directions for Institutional Research, 2011(149), 65-79. https://doi.org/10.1002/ir.381
Deardorff, D. K., \& Deardorff, D. L. (2007). An overview of the basic methods of outcomes assessment. In M. C. Bolen (Ed.), A guide to outcomes assessment in education abroad (pp. 89-96). Carlisle, PA: Forum on Education Abroad.

Dervin, F. (2010). Assessing intercultural competence in language learning and teaching: A critical review of current efforts. New Approaches to Assessment in Higher Education, 5, 155-172.

Dickmann, M.F. (2021). Cross-border deployment of talent in times of crisis. RES Forum Annual Report Research 2021 (https://theresforum.com/ annual-report/).

Fantini, A. E. (2006). Assessment tools of intercultural communicative competence. Federation of the experiment in international living: occasional papers.

Fantini, A. E. (2009). Assessing intercultural competence: Issues and tools. In D. K. Deardorff (Ed.), The SAGE Handbook of Intercultural Competence (pp. 456-476). Thousand Oaks, CA: Sage.

Feitosa, J., Kreutzer, C., Kramperth, A., S. Kramer, W., \& Salas, E. (2014). Expatriate adjustment: Considerations for selection and training. Journal of Global Mobility, 2(2), 134-159. https://doi. org/10.1108/JGM-06-2013-0042

Gertsen, M. C. (1990). Intercultural competence and expatriates. The International Journal of Human Resource Management, 1(3), 341-362. https://doi. org/10.1080/09585199000000054

Graf, A., \& Harland, L. K. (2005). Expatriate selection: Evaluating the discriminant, convergent, and predictive validity of five measures of interpersonal and intercultural competence. Journal of Leadership \& Organizational Studies, 11(2), 4662. https://doi.org/10.1177/107179190501100206

Griffith, R. L., Wolfeld, L., Armon, B. K., Rios, J., \& Liu, O. L. (2016). Assessing intercultural competence in higher education: Existing research and future directions. research report. ETS RR16-25. ETS Research Report Series. https://doi. org/10.1002/ets2.12112

Guntersdorfer, I., \& Golubeva, I. (2018). Emotional intelligence and intercultural competence: Theoretical questions and pedagogical possibilities. UMBC Faculty Collection. https://doi. org/10.29140/ice.v1n2.60

Harris, H., \& Brewster, C. (1999). The coffee-machine system: how international selection really works. International Journal of Human Resource Management, 3, 488. https://doi. org/10.1080/095851999340440

Hofstede, G. (1983). National cultures in four dimensions: A research-based theory of cultural differences among nations. International Studies 
of Management \& Organization, 13(1-2), 46-74. https://doi.org/10.1080/00208825.1983.11656358

IOR Global Services. (2015). Assessment tools for global talent, or IOR Global Services Assessment_Collateral_with_Tools_Chart.pdf. IOR Global Services. Retrieved 24 March 2018 from www.iorworld.com.

Johnson, J. P., Lenartowicz, T., \& Apud, S. (2006). Cross-cultural competence in international business: Toward a definition and a model. Journal of International Business Studies, 37(4), 525-543. https://doi.org/10.1057/palgrave.jibs.8400205

Josien, L. (2012). Enhancing expatriate selection: Measuring the strength of acculturation. Journal of International Business Research, 11(1), 83.

KIT Royal Tropical Institute. (n.d.) Multicultural Personality Questionnaire (MPQ). Retrieved 29 July 2019 from https://www.kit.nl/service/multicultural-personality-questionnaire-mpq/

Kraimer, M., Bolino, M., \& Mead, B. (2016). Themes in expatriate and repatriate research over four decades: What do we know and what do we still need to learn? Annual Review of Organizational Psychology \& Organizational Behavior, 3, 83. $\quad$ https://doi.org/10.1146/annurev-orgpsych-041015-062437

Lieberman, D. A., \& Garnst, G. (2015). Intercultural communication competence revisited: Linking the intercultural and multicultural fields. International Journal of Intercultural Relations: IJIR, 48, 17. https://doi.org/10.1016/j.ijintrel.2015.03.007

Linville, M. W. (2012). An Examination of How Personality Factors Influence the Adaptability of U.S. National Leaders in Expatriate Contexts. (Dissertation). Indiana Wesleyan University in Marion, Indiana.

Matsumoto, D., \& Hwang, H. C. (2013). Assessing cross-cultural competence: A review of available tests. Journal of Cross-Cultural Psychology, 44(6), 849-873. https://doi. org/10.1177/0022022113492891

McNulty, Y., De Cieri, H., \& Hutchings, K. (2013). Expatriate return on investment in the Asia Pacific: An empirical study of individual ROI versus corporate ROI. Journal of World Business, 48(2), 209221. https://doi.org/10.1016/j.jwb.2012.07.005

Mello, J. A. (2014). Strategic human resource management. Toronto: ON. Nelson Education.

Mesmer-Magnus, J. R., \& Viswesvaran, C. (2008). Expatriate management: A review and directions for research in expatriate selection, training, and repatriation. Handbook of Research in International Human Resource Management, 183-206.
Mokkink, L. B., Terwee, C. B., Patrick, D. L., Alonso, J., Stratford, P. W., Knol, D. L., de Vet, H. C. (2010). The COSMIN study reached international consensus on taxonomy, terminology, and definitions of measurement properties for health-related patient-reported outcomes. Journal of Clinical Epidemiology, 63(7), 737-745. https://doi. org/10.1016/j.jclinepi.2010.02.006

Nelson, P. (2019). The relationship of state fragility and Hofstede's index of cultural distance to cross-cultural adjustment of expatriates. Rosemead School of Psychology, Biola University, La Mirada, California.

Paige, R. M. (2004). Instrumentation in intercultural training. In Landis, D., Bennett, J., \& Bennett, M. (Ed.), Handbook of intercultural training (pp. 85-128). Sage Publications. https://doi. org/10.4135/9781452231129.n4

Peltokorpi, V., \& Froese, F. J. (2012). The impact of expatriate personality traits on cross-cultural adjustment: A study with expatriates in Japan. International Business Review, 21(4), 734746. https://doi.org/10.1016/j.ibusrev.2011.08.006

Pennington, D. (2018). Essential personality. Abingdon-on-Thames: UK. Routledge. https://doi. org $/ 10.4324 / 9780203784624$

Perry, L. B., \& Southwell, L. (2011). Developing intercultural understanding and skills: Models and approaches. Intercultural Education, 22(6), 453466. https://doi.org/10.1080/14675986.2011.644 948

Selmer, J. (2001). The preference for predeparture or postarrival cross-cultural training-an exploratory approach. Journal of Managerial Psychology, 16(1), 50-58. https://doi. org/10.1108/02683940110366560

Sercu, L. (2004). Assessing intercultural competence: A framework for systematic test development in foreign language education and beyond. Intercultural Education, 15(1), 73. https:// doi.org/10.1080/1467598042000190004

Stuart, D. (2008). Assessment instruments for the global workforce. In M. Moodian (Ed.), Contemporary Leadership and Intercultural Competence, (pp. 175-190). Sage Publications. https://doi. org/10.1080/1467598042000190004

Sutton, R. C., Miller, A. N., \& Rubin, D. L. (2007). Research design in assessing learning outcomes of education abroad programs. In M. C. Bolen (Ed.), A guide to outcomes assessment in education abroad (pp. 89-96). Carlisle, PA: Forum on Education Abroad. https://doi.org/10.4135/9781452274942. n14

Tamas Consultants. (n.d.). Description of the Multicultural Personality Questionnaire (MPQ). 
Tamas Consultants. Retrieved July 29, 2019, from www.tamas.com/sites/default/files/MPQ.pdf.

The roadmap to intercultural competence using the IDI: success stories: testimonials. (2019). Retrieved from https://idiinventory.com/success-stories/testimonials/.

Tung, R. L. (1981). Selection and Training of Personnel for Overseas Assignments. Columbia Journal of World Business, 16(1), 68-78.

Van der Zee, K., Van Oudenhoven, J. P., Ponterotto, J. G., \& Fietzer, A. W. (2013). Multicultural personality questionnaire: Development of a short form. Journal of Personality Assessment, 95(1), 118-124. https://doi.org/10.1080/00223891.2012. 718302

Wang, Y., \& Kulich, S. J. (2015). Does context count? developing and assessing intercultural compe- tence through an interview- and model-based domestic course design in China. International Journal of Intercultural Relations: IJIR, 48, 38. https:// doi.org/10.1016/j.ijintrel.2015.03.013

$\mathrm{Yu}, \mathrm{H}$. (2012). Intercultural competence in technical communication: A working definition and review of assessment methods. Technical Communication Quarterly, 21(2), 168-186. https://doi.org/10.1080 /10572252.2012.643443

\section{Review}

This article was accepted under the constructive peer review option. For futher details, see the descriptions at:

http://mumabusinessreview.org/peer-review-options/

\section{Acknowledgments}

This author thanks Dr. Dejun "Tony" Kong, Dr. Denise Breckon, and the reviewers of the Informing Science Institute for their many helpful suggestions.

\begin{tabular}{|l|l|} 
Author \\
\hline
\end{tabular}

